Vol. 6, No. 1 Januari - Juni 2017

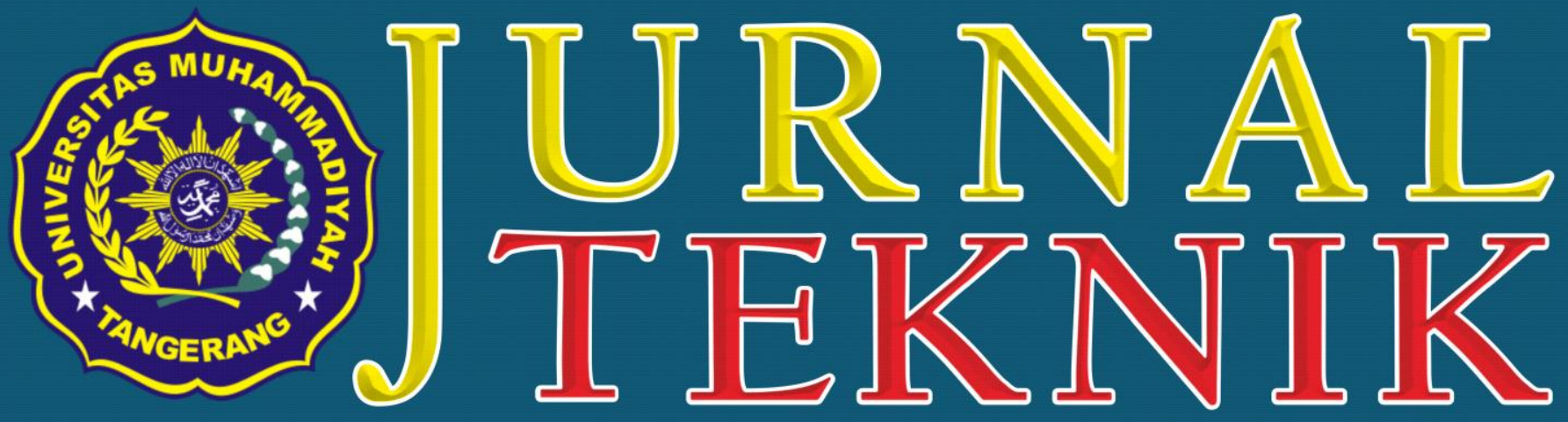

Alamat Redaksi: Jl. Perintis Kemerdekaan I No. 33, Cikokol Tangerang - TIp. (021) 51374916

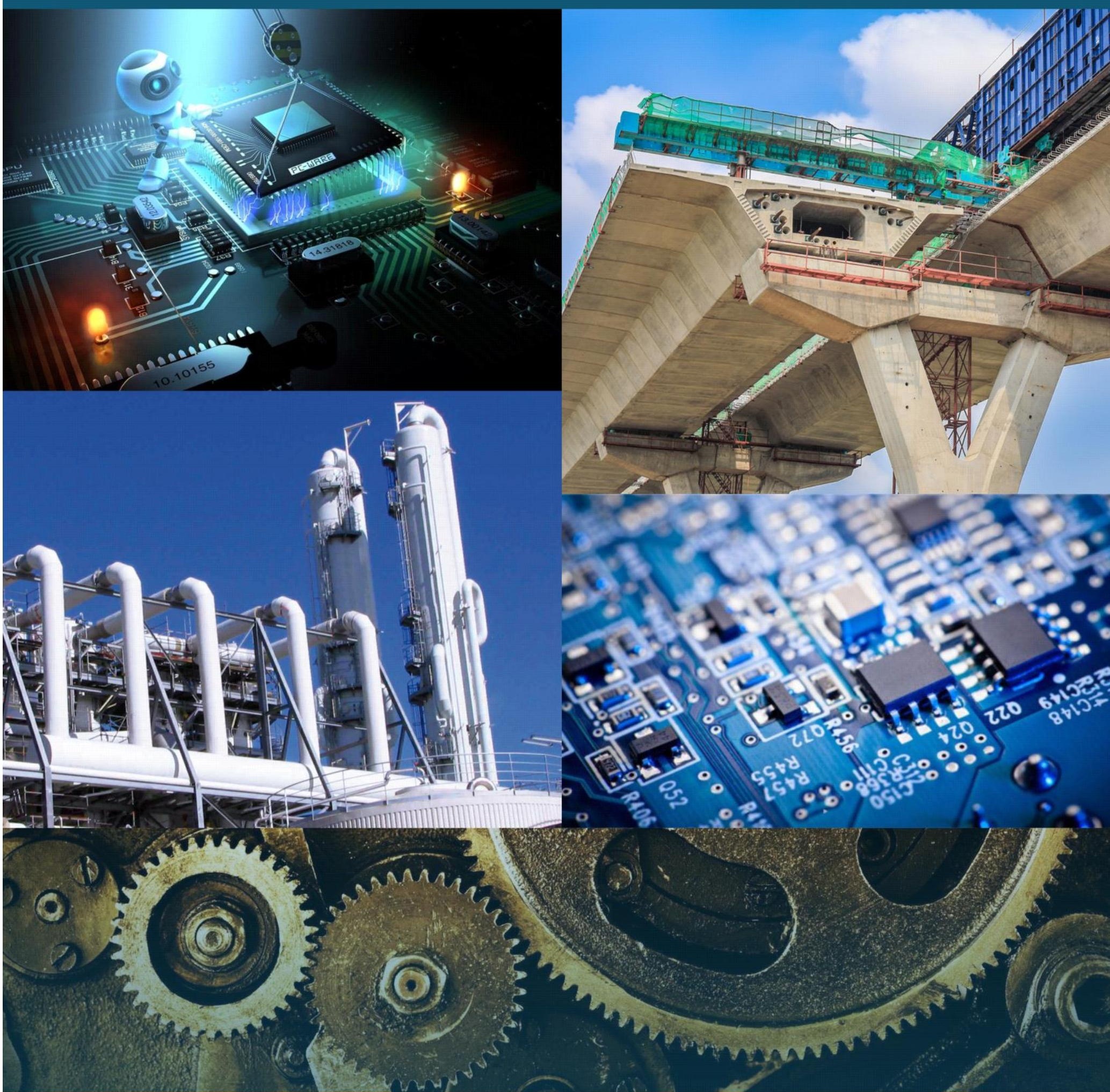




\section{J U R N A L TEKN I K}

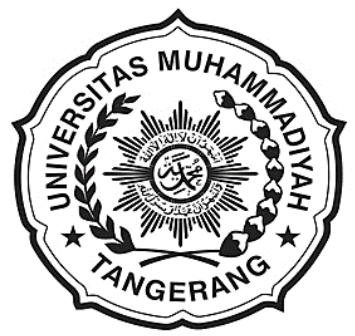

\section{UNIVERSITAS MUHAMMADIYAH TANGERANG}

Pelindung:

Dr. H. Achmad Badawi, S.Pd., SE., MM. (Rektor Universitas Muhammadiyah Tangerang)

Penanggung Jawab:

Ir. Saiful Haq, ST., M.Si.

(Dekan Fakultas Teknik)

Pembina Redaksi:

Rohmat Taufik, ST., M.Kom.

Drs. H. Syamsul Bahri, MSi.

Pimpinan Redaksi:

Ir. Sumardi Sadi, S.Pd., ST., MT.

Redaktur Pelaksana:

Yafid Efendi, ST, MT.

Editor Jurnal Teknik UMT:

Ir. Sumardi Sadi, S.Pd., ST., MT.

Dewan Redaksi:

Ir. Ali Rosyidin, ST., MM., MT.

Tri Widodo, ST.,MT.

Tina Herawati, ST., MT

Almufid, ST., MT.

Siti Abadiah, ST., MT.

M. Jonni, SKom., MKom.

Syepry Maulana Husain, S.Kom., M.Kom.

Ir. H. Bayu Purnomo, ST., MT

Kasubag:

Ferry Hermawan, MM.

Keuangan:

Elya Kumalasari, S.Ikom.

Setting \& Lay Out:

Muhlis, S.E

Saiful Alam, SE.

Mitra Bestari:

Prof. Dr. Aris Gumilar

Ir. Doddy Hermiyono, DEA

Dr. Ir. Budiyanto, MT.

Dr. Alimuddin, ST., MM., MT

J U R N A L T E K N I K

Diterbitkan Oleh:

Fakultas Teknik Universitas Muhammadiyah Tangerang

Alamat Redaksi:

Jl. Perintis Kemerdekaan I No. 33, Cikokol Tangerang Tlp. (021) 51374916

\begin{tabular}{|c|c|c|c|c|c|}
\hline \multirow{2}{*}{$\begin{array}{c}\text { Jurnal } \\
\text { Teknik }\end{array}$} & 6 & 1 & $1-97$ & $\begin{array}{c}\text { Jan'-Juni } \\
2017\end{array}$ & ISSN \\
\cline { 2 - 6 } & $2302-8734$ \\
\hline
\end{tabular}

\section{DAFTAR ISI}

1. PROSES PEMBUATAN ALAT PEMBUKA KALENG CAT DENGAN METODE CETAK PASIR (SAND CASTING) - 1-11 Ali Rosyidin

2. ANALISA DAN PERANCANGAN SISTEM KENDALI PLC XBC MINI BAS - 12-18 Alim Hardiansyah \& Bambang Suardi Waluyo

3. PENGATUR KESTABILAN SUHU PADA EGG INCUBATOR BERBASIS ARDUINO - 19-22

Abel Putra Hidayah \& Sumardi Sadi

4. METODE PEMBUATAN PONDASI BORE PILE DENGAN KINGPOST DAN METODE PONDASI DINDING PENAHAN TANAH DIAFRAGMA WALL - 23-29

Almufid

5. RANCANG BANGUN SIMULASI PENGENDALI LAMPU LALU LINTAS PADA PERSIMPANGAN DENGAN LIMA JALUR - 30-39

Rahma Farah Ningrum, Puji Catur Siswipraptini, \& Rosida N. Aziza

6. PERANCANGAN PROGRAM APLIKASI PENGENALAN WAJAH DENGAN MENERAPKAN METODE PRINCIPAL COMPONENT ANALYSIS DAN JARINGAN SYARAF TIRUAN - 40-49

M. Lutfi Aksani

7. KAJIAN PENERAPAN SI / TI DALAM MENINGKATKAN KUALITAS PEMBELAJARAN PADA TRAINING CENTER DENGAN MENGGUNAKAN METODOLOGI DeLone And McLean: STUDI KASUS PADA BINUS CENTER JAKARTA - 50-62 Nyoman Ayu Gita Gayatri \& GG Faniru Pakuning Desak

8. RANCANG BANGUN APLIKASI PEMBELAJARAN MATEMATIKA SD KELAS 6 BERBASIS ANDROID PADA SDN CIMONE 1 TANGERANG - 63-69

Winda Anggraeni \& Sri Mulyati

9. RANCANG BANGUN MESIN PERAJANG SINGKONG INDUSTRI RUMAHAN BERDAYA RENDAH - 70-76

Yafid Effendi \& Agus Danang Setiawan

10. RANCANG BANGUN TONGKAT ULTRASONIK UNTUK PENYANDANG TUNA NETRA BERBASIS ARDUINO UNO - 77-82

Bayu Purnomo \& Basuki Isnanto

11. ENTERPRISE RISK MANAGEMENT PADA CLOUD COMPUTING - 83-87

Samudera Dipa Legawa

12. ANALISIS NETWORK PLANNING DENGAN CRITICAL PATH METHOD (CPM) PADA PROYEK UNINTERATUBLE POWER SUPPLY (UPS) 80KVA PADA PT. HARMONI MITRA SUKSES (STUDI KASUS: RSAB HARAPAN KITA, JAKARTA) - 88-97

Hermanto, Novy Fauziah, \& Elfitria Wiratmani 


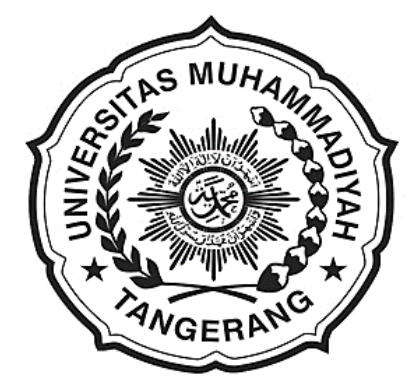

\section{Sambutan Dekan \\ Fakultas Teknik \\ Universitas Muhammadiyah Tangerang}

Puji Syukur kehadirat Allah Swt. karena berkat karunia dan ijin-Nyalah Tim penyusun Jurnal Teknik Fakultas Teknik Universitas Muhammadiyah Tangerang dapat menyelesaikan tugasnya tepat sesuai dengan waktu ditetapkan.

Saya menyambut baik diterbitkannya Jurnal Teknik Vol. 6 No. 1, Januari-Juni 2017, terbitnya jurnal ini, merupakan respon atas terbitnya Peraturan Menteri Pendidikan Nasional No. 17 Tahun 2010 tentang Pencegahan dan Penanggulangan Plagiat di Perguruan Tinggi; Surat Dirjen Dikti Nomor 2050/E/T/2011 tentang kebijakan unggah karya ilmiah dan jurnal; Surat Edaran Dirjen Dikti Nomor 152/E/T/2012 tertanggal 27 Januari 2012 perihal publikasi karya ilmiah yang antara lain menyebutkan untuk lulusan program sarjana terhitung mulai kelulusan setelah 2012 harus menghasilkan makalah yang terbit pada jurnal ilmiah.

Terbitnya Jurnal ini juga diharapkan dapat mendukung komitmen dalam menunjang peningkatan kemampuan para dosen dan mahasiswa dalam menyusun karya ilmiah yang dilandasi oleh kejujuran dan etika akademik. Perhatian sangat tinggi yang telah diberikan rektor Universitas Muhammadiyah Tangerang khususnya mengenai plagiarism dan cara menghindarinya, diharapkan mampu memacu semangat dan motivasi para pengelola jurnal, para dosen dan mahasiswa dalam menyusun karya ilmiah yang semakin berkualitas.

Saya mengucapkan banyak terimakasih kepada para penulis, para pembahas yang memungkinkan jurnal ini dapat diterbitkan, dengan harapan dapat dimanfaatkan seoptimal mungkin dalam peningkatan kualitas karya ilmiah.

Dekan Fakultas Teknik

Universitas Muhammadiyah Tangerang,

\section{Ir. Saiful Haq, M.Si.}




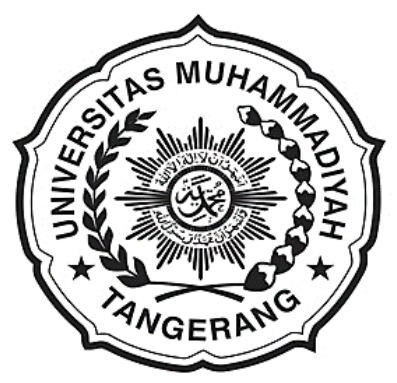

\section{Pengantar Redaksi}

Jurnal Teknik

Universitas Muhammadiyah Tangerang

Puji dan Syukur Alhamdulillah kami panjatkan kehadapan Allah Swt. atas karunia dan lindungan-Nya sehingga Jurnal Teknik Vol. 6 No. 1 edisi Januari-Juni 2017 dapat diterbitkan.

Menghasilkan karya ilmiah merupakan sebuah tuntutan perguruan tinggi di seluruh dunia. Tri Dharma Perguruan Tinggi yaitu darma pendidikan, darma penelitian, dan darma pengabdian kepada masyarakat mendorong lahirnya dinamika intelektual diantaranya menghasilkan karyakarya ilmiah. Penerbitan Jurnal Teknik ini dimaksudkan sebagai media dokumentasi dan informasi ilmiah yang sekiranya dapat membantu para dosen, staf dan mahasiswa dalam menginformasikan atau mempublikasikan hasil penelitian, opini, tulisan dan kajian ilmiah lainnya kepada berbagai komunitas ilmiah.

Buku Jurnal yang sedang Anda pegang ini menerbitkan 12 artikel yang mencakup bidang teknik sebagaimana yang tertulis dalam daftar isi dan terdokumentasi nama dan judul-judul artikel dengan jumlah halaman 1-97 halaman.

Jurnal Teknik ini tentu masih banyak kekurangan dan masih jauh dari harapan, namun demikian tim redaksi berusaha untuk ke depannya menjadi lebih baik dengan dukungan kontribusi dari semua pihak. Harapan Jurnal Teknik akan berkembang menjadi media komunikasi intelektual yang berkualitas, aktual dan faktual sesuai dengan dinamika di lingkungan Universitas Muhammadiyah Tangerang.

Tak lupa pada kesempatan ini kami mengundang pembaca untuk mengirimkan naskah ringkasan penelitiannya ke redaksi kami. Kami sangat berterimakasih kepada semua pihak yang telah membantu penerbitan Jurnal Teknik ini semoga buku yang sedang Anda baca ini dapat bermanfaat.

Pimpinan Redaksi Jurnal Teknik

Universitas Muhammadiyah Tangerang,

Ir. Sumardi Sadi, S.Pd., ST., MT. 


\title{
METODE PEMBUATAN PONDASI BORE PILE DENGAN KINGPOST DAN METODE PONDASI DINDING PENAHAN TANAH DIAFRAGMA WALL
}

\author{
Almufid \\ Program Studi Teknik Sipil \\ Universitas Muhammadiyah Tangerang \\ Jl. Perintis Kemerdekaan I/33, Cikokol - Tangerang-Banten \\ E-mail : almufid_st@yahoo.com
}

\begin{abstract}
ABSTRAK
Metode pekerjaan pondasi bored pile dengan kingpost, dan metode pembuatan dinding penahan tanah (diaphragma wall) di proyek Indonesia . Material baja kingpost kedalam lubang bored pile, agar dapat dilaksanakannya metode topdown pada saat pengalian dilakukan pada proyek Bangunan Tinggi pada kondisi Tanah Lunak, sehingga dapat mempercepat pembangunan gedung Tinggi Manfaat dari dinding penahan tanah (diaphragm wall) yang nantinya akan menjadi dinding basement, Pada Bangunan Tinggi Kostruksi bangunan gedung seperti yang kita ketahui memulai pembangunan dari bagian bawah menuju bagian bangunan atas (bottom-up). Namun seiring berkembangnya ilmu pengetahuan manusia. Maka diciptakan metode konstruksi top-down atau dari atas kebawah. Untuk memenuhi metode kontruksi top-down perlu adanya kingpost yang terdiri dari fropil baja yang nantinya dipasang bersamaan ditengah tengah pondasi bored pile. Setelah selesai pengecoran. Material kingpost adalah kompenen utama dari system pekerjaan top-down. Tanpa adanya kingpost, rasanya mustahil dapet terlaksanakan sebuah system top-down pelaksanaan bangunan yang mempunyai banyak keuntungan dari sudut biaya dan waktu
\end{abstract}

Kata Kunci: Bangunan Tinggi, Pondasi bored pile, King Post, dan Top-Down.

\section{LATAR BELAKANG}

Konstruksi pondasi yang digunakan pada proyek Indonesia satu . Pondasi bored pile. Pondasi bored pile sendiri adalah jenis pondasi dalam yang berbentuk tabung, berfungsi meneruskan beban struktur bangunan diatasnya dari permukaan tanah sampai lapisan tanah keras di bawahnya. Pengerjaan pondasi dalam khususnya pondasi bored pile tidak biasa dikerjaan secara sembarangan tanpa perhitungan dan perencanaan yang matang. Oleh karena itu, diperlukan metode metode serta tahapan untuk melaksanakan penggalian pondasi bored pile. Setiap proyek juga memiliki tingkat kesulitan lahan serta daerah yang berbeda pula untuk melakukan pekerjaan pondasi bored pile. Selain lahan, alat yang digunakan juga harus Pondasi ini sangat cocok digunakan untuk lokasi yang disekitarnya rapat dengan bangunan lain, pemukiman warga karena proses pembuatan pondasi ini tidak menimbulkan efek getar yang besar.

Kostruksi bangunan gedung seperti yang kita ketahui memulai pembangunan dari bagian bawah menuju bagian bangunan atas (bottom-up). Namun seiring berkembangnya ilmu pengetahuan manusia. Maka diciptakan metode konstruksi top-down atau dari atas kebawah. Untuk memenuhi metode kontruksi top-down perlu adanya kingpost 
yang terdiri dari fropil baja yang nantinya dipasang bersamaan ditengah tengah pondasi bored pile. Setelah selesai pengecoran. Material kingpost adalah kompenen utama dari system pekerjaan top-down. Tanpa adanya kingpost, rasanya mustahil dapet terlaksanakan sebuah system top-down pelaksanaan bangunan yang mempunyai banyak keuntungan dari sudut biaya dan waktu.

Contoh Pada Kontruksi bangunan gedung pencakar langit pada proyek Indonesia Satu bukan saja bangunan yang semakin tinggi, juga makin dirasakan perlunya pembuatan basement yang dalam lagi. Semakin dalam basemant dituntut pengunaan teknologi ekskavasi yang lebih cangih, Baik pertimbangan dari kepraktisan pelaksanaan maupun biayanya. Pada umumnya dinding penahan tanah dipakai untuk kontruksi bangunan dibawah permukaan tanah (basement). Diaphragm wall dalam dunia konstruksi dikenal sebagai dinding yang berfungsi ganda yaitu sebagai penahan tanah (retaining wall) dan berfungsi sebagai dinding pada lantai basement bangunan yang mempunyai lantai bawah tanah lebih dari tiga basement.

\section{TUJUAN DAN MANFAAT PENULISAN}

Pondasi dalam adalah pondasi yang didirikan di permukaan tanah dengan kedalaman tertentu dimana daya dukung dasar pondasi dipengaruhi oleh beban struktural dan kondisi permukaan tanah, Pondasi dalam biasanya dipasang pada kedalaman lebih dari $3 \mathrm{~m}$ di bawah elevasi permukaan tanah. Pondasi dalam dapat dijumpai dalam bentuk Pondasi tiang pancang, Dinding pancang, dan Caissons dan Pondasi King Post

Pada dasarnya, Bagian-bagian konstruksi bangunan meliputi bangunan bawah dan bangunan atas. Bangunan bawah adalah bagian bangunan yang terletak di bawah permukaan tanah. Sedangkan bangunan atas merupakan bagian bangunan yang berada di atas permukaan tanah.

Bagian suatu Struktur bangunan yang terletak di bawah permukaan tanah. yaitu Bangunan dibawah berguna untuk menopang bangunan diatasnya sehingga harus mempunyai struktur yang kuat, tidak mudah bergerak, dan kondisinya stabil, yang termasuk bagian bangunan bawah meliputi struktur Tanah, pondasi dan basement. Di bawah ini penjelasan singkat mengenai bagian-bagian dari bangunan bawah tersebut.

\subsection{Pengertian King Post}

King post merupakan rangkaian dari pekerjaan pondasi bored pile untuk pelaksanaan metode top-down, king post merupakan baja berbentuk H-beam. King post adalah bagian dari tiang pondasi pada posisi kolom basement, Yang biasanya terbuat dari profil baja. King post ini berfungsi untuk mendukung pelat lantai dan kolom sementara, Yang nantinya diperkuat agar berfungsi sebagai kolom permanen.

Fungsi pelat pada lantai beton pada sistem konstruksi top down sangat penting, Karena bukan saja berfungsi sebagai lantai untuk menahan beban matinya, Tetapi juga sebagai penopang yang menahan deformasi lateral pada saat pelaksanaan pekerjaan galian tanah. Struktur basement pada metode top down dilakukan dari basement yang teratas dan dilanjutkan lapis demi lapis sampai kedalaman basement yang di inginkan.

\subsection{Metode Pelaksanaan Podasi Dalam dengan Bore Pile dan King Post}

pengeboran awal dilakuakan dengan mengunakan bucket auger sampai batas kedalaman muka air tanah/ sampai batas kedalam casing yang dipakai pada titik bored pile.

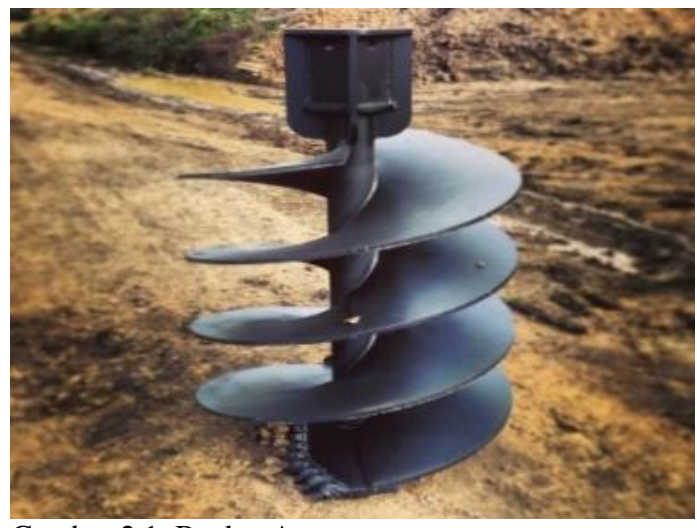

Gambar 2.1 Bucket Auger. 
Pengeboran dilanjutkan dengan memasukan casing dengan kedalam lubang yang sudah dibor, Kegunaan dari casing agar menahan permuakaan tanah atas selama proses pengeboran berlangsung dan untuk mentukan elevasi kedalaman lubang dan cut of level pada titik bored pile.

Casing yang sudah terpasang dicabut setelah beres pengecoran titik bored pile non kingpost sedangakan untuk titik bored pile dengan kingpost, casing harus menungu $3 \times 24$ jam atau menunggu back pile titik bored pile dengan kingpost

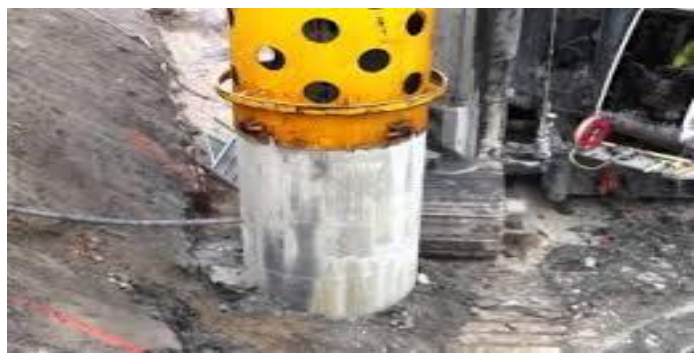

Gambar 2.2 Pemasang Casing

Setalah proses pemasang casing selesai pengeboran dilanjut dengan mengunakan drilling bucket, Sampai kedalaman bore sesuai rencana design yang diinginkan. Pengukuran kedalaman lubang diukur menggunakan meteran rol.

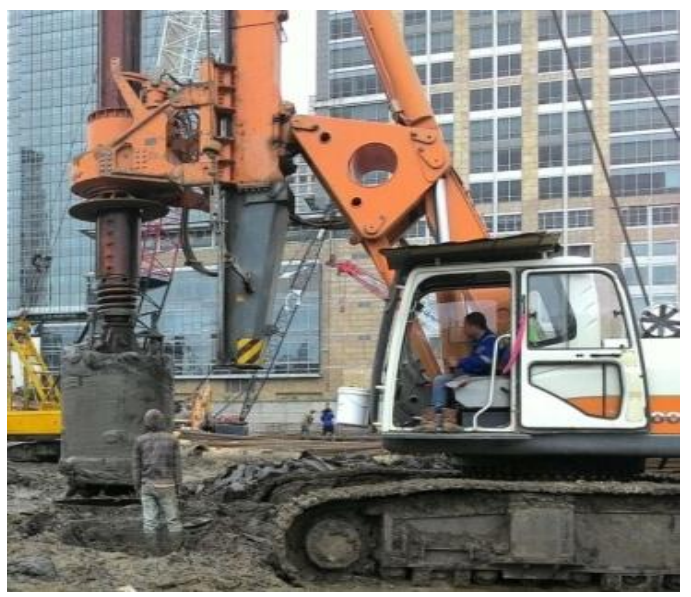

Gambar 2.3 Drilling Bucket

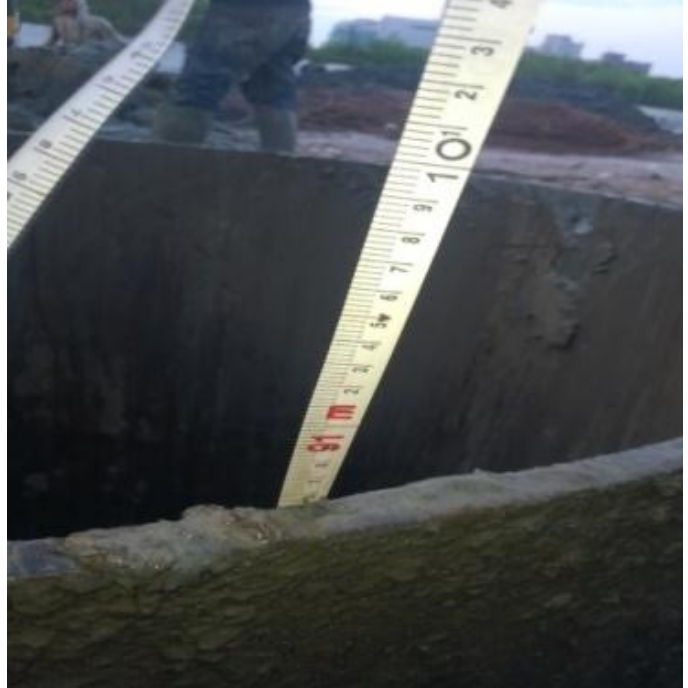

Gambar 2.4 Meteran Rol

\subsubsection{Slurry Bentonite dan Polimery}

Selama pengeboran berlangsung, campuran slurry yang digunakan pada proyek Bangunan Tinggi Slurry yang digunakan berbentuk campuran bentonite, polimery dan air. Slurry di-supply ke dalam lubang bor untuk memberikan tegangan keliling pada selimut lubang agar tanah disekitarnya tidak mudah longsor. Slurry harus dijaga tetap berada di atas muka air tanah agar dapat bekerja secara maksimal.

Adapun bentuk bentuk pengetesan pada material slurry agar mendapatkan hasil yang telah ditentukan oleh perencana.

a. Pengecekan density/ berat jenis (1.01 $\mathrm{s} / \mathrm{d} 1.10 \mathrm{~g} / \mathrm{ml}$ );

b. Pengecekan PH (8 s/d 11);

c. Pengecekan Viskositas (30 s/d 50 seconds);

d. Sand Content (2 s/d $4 \%)$;

e. Filter cake $(2 \mathrm{~s} / \mathrm{d} 4 \mathrm{~mm})$; dan

f. Fluid loos $(30 \mathrm{~s} / \mathrm{d} 50 \mathrm{ml})$.

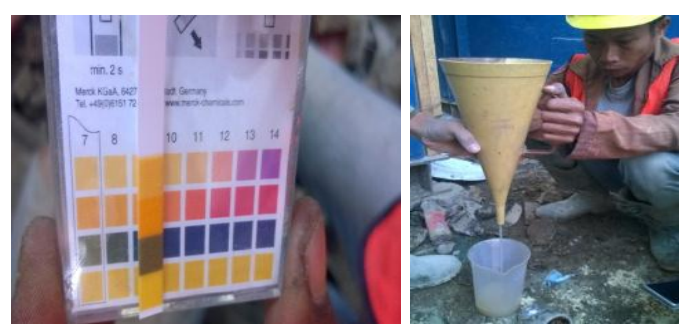

Gambar 2.5 Pengetesa PH \& Pengetesan Viskositas. 


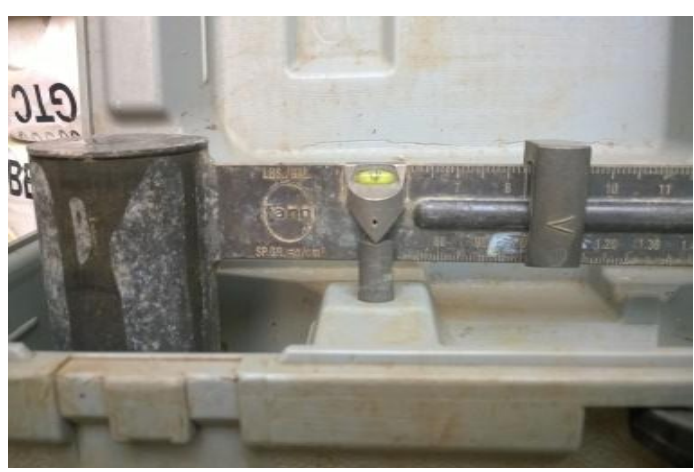

Gambar 2.6 Pengetesan Berat Jenis.

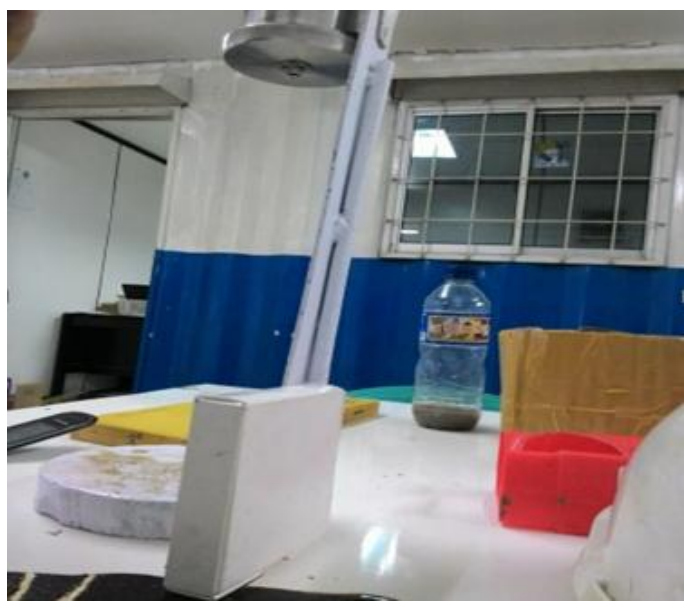

Gambar 2.7 Pengetesan Fluid Loss

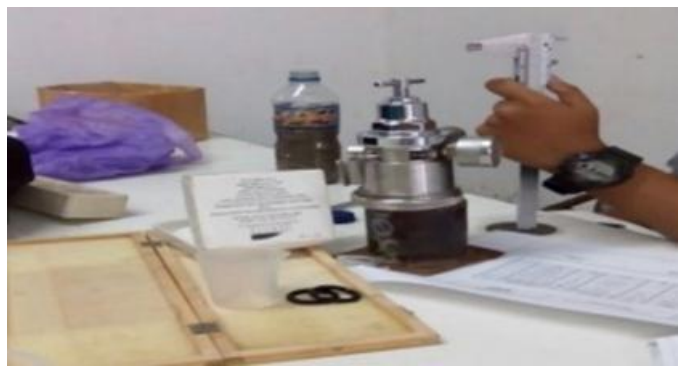

Gambar 2.8 Pengetesan Filter Cake

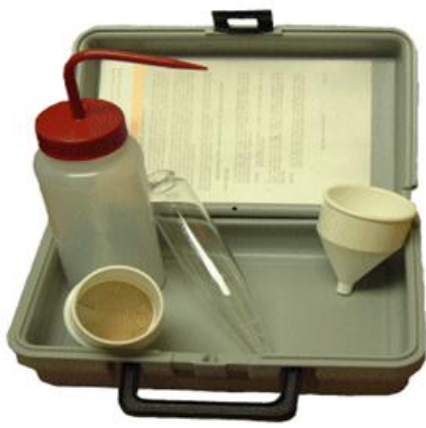

Gambar 2.9 Pengetesan Sand Conten

2.2.2 Pembersihan Lubang Bored Pile/ Drilling Cleaning

Pembersihan lubang/ drilling cleaning dilakukan setalah kedalam lobang bored pile yang telah mencapai sesuai kedalaman design. Pengeboran dilakukan mengunakan drilling bucket cleaning, Pembersihan lubang dilakukan untuk mengangkan endapan endapan yang teleh mengendap pada saat proses pengeboran berlangsung. Setelah selesai melakukan cleaning mengukur kembali kedalaman yang sudah diukur sebelomnya.

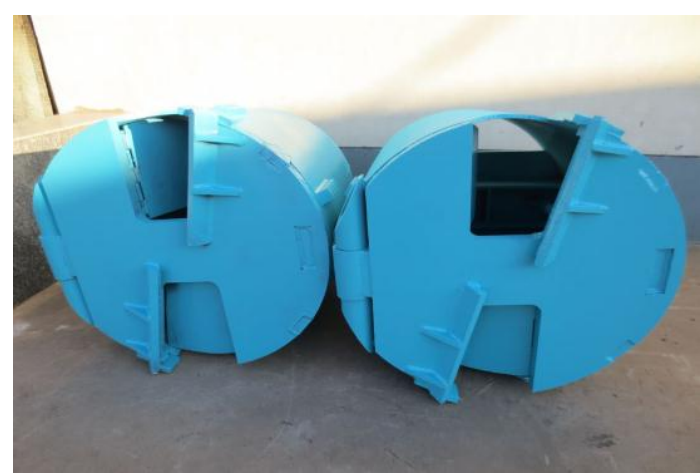

Gambar 2.10 Bucket Drilling Bucket Clening

\subsubsection{Pekerjaan Pembesian Bored Pile \& King Post}

Pembesian bored pile dan pada Pembesian dipastikan harus ada beton decking disetiap rangkaian tulangan. Perakitan pembesian tulangan dilakuakan selama proses pengeboran. Tulangan pembesian dimasukan kedalam lubang bored pile setelah pembersihan dasar lubang dan kedalaman lobang telah mencapai sesuai rencana design.

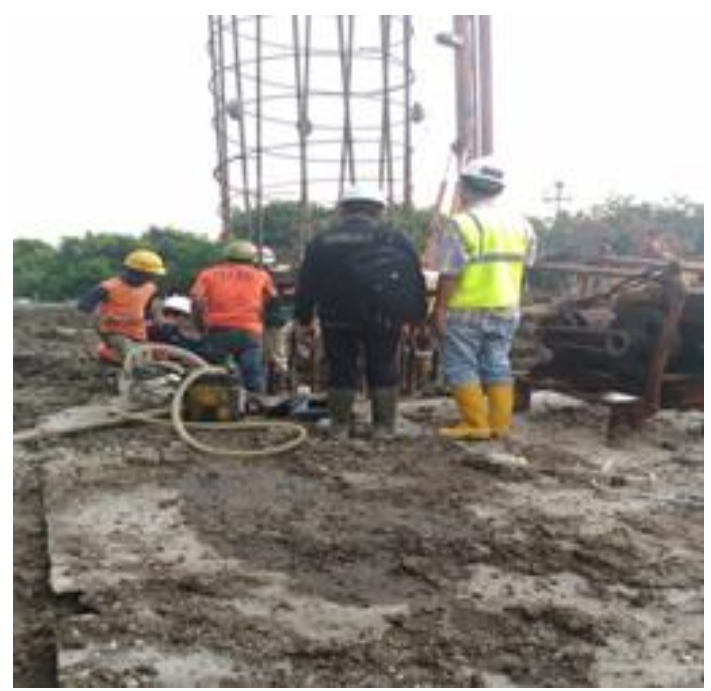

Gambar 2.11 Pemasangan Besi Menggunakan Join Fuji Bolt 


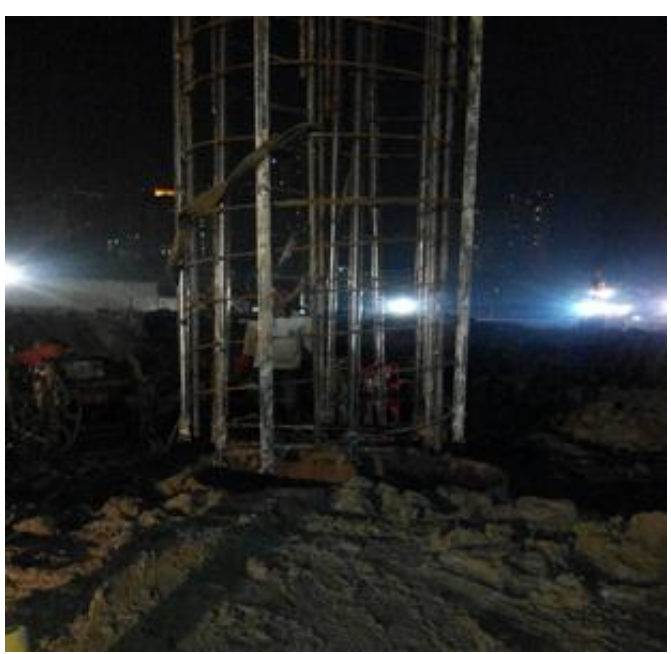

Gambar 2.12 Tulangan Pembesian Kedalam Lubang Bored Pile

\subsubsection{Pengecoran Bored Pile}

a. Sebelum pengecoran dilakukan, setiap read mix tiba di proyek penulis melakukan pengecekan mutu beton slump test, Slump test pada proyek indonesia satu $18 \pm 2 \mathrm{~cm}$ untuk titik bore pile biasa atau non kingpost, Sedangkan untuk beton bore pile dengan kingpost mutu beton slump test $20 \pm 2 \mathrm{~cm}$. Suplayer beton yang digunakan di proyek indonesia pionir beton hanya mengunakan satu suplayer beton. Pemesanan beton dilakukan pada saat pemasangan pipa tremie kedalam lobang bored pile, beton yang diorder oleh pihak kontraktor $\pm 120 \mathrm{~m}^{3}$ mutu Fc'35 mpa.

b. Setelah melakukan pengecekan slump test, Penulis melakukan pengecekan kualitas lobang bored pile, Dengan cara mengukur kembali kedalaman lobang bored pile. Lobang bore pile harus tetap sesuai dengan kedalaman awal setalah proses cleaning.

c. Setelah proses pengecekan mutu beton dan kedalaman lobang bore pile, Penulis mengijinkan pelaksanaan pengecoran dilakukan, Penulis mengecek kedalaman setiap selesai penuangan beton read mix permobil kedalam lobang bored pile, Guna memastikan kenaikan beton yang terjadi dalam satu mobil read mix yang tertuang, dan memastikan pipa tremie yang tertanam didalam beton tidak terlalu panjang agar tidak terjadi rongga saat galian berlangsung. pengecoran berlangsung sampai batas top cor yang sudah disepakati oleh pihak pihak yang terlibat dalam proyek indonesia satu, Batas top cor dari cut of level $\pm 1.5 \mathrm{~m}$.

\section{Kingpost}

\subsection{Pekerjaan Kingpost}

Kingpost merupakan material tambahan yang digunakan pada proyek Indonesia satu, Kingpost yang terdiri dari fropil baja yang nantinya dipasang bersamaan ditengah tengah lobang pondasi bored pile.

Setelah selesai pengeboran, Pemasangan keranjang besi, Pemasangan pipa tremi, pengecoran pondasi bored pile selesai, lalu dilakukan pemasangan material kingpost yang merupakan kompenen utama dari system pekerjaan top-down.

\section{Contoh Bentuk King Posh}

\begin{tabular}{|c|c|c|c|c|c|c|}
\hline No & TYPE & DIMENSI & $\begin{array}{l}\text { TOP PLATE } \\
\text { ELEVATION }\end{array}$ & LOCATION & LENGTH & JUMLAH \\
\hline 1 & KP1A2 & $350 \times 350 \times 35$ & -5.05 & PODIUM & 22.58 & 85 \\
\hline 2 & KP1A3 & $350 \times 350 \times 35$ & -5.05 & PODIUM & 23.78 & 2 \\
\hline 3 & KP1A4 & $350 \times 350 \times 35$ & -5.05 & PODIUM & 24.61 & 1 \\
\hline 4 & KP1A5 & \begin{tabular}{|l|l|}
$550 \times 350 \times 35$ \\
\end{tabular} & -5.05 & TOWER & 23.8 & 2 \\
\hline 5 & KP1A & \begin{tabular}{|l}
$350 \times 350 \times 35$ \\
\end{tabular} & -5.05 & TOWER & 23.78 & 22 \\
\hline 6 & KP1B & \begin{tabular}{|l|l}
$350 \times 350 \times 35$ \\
\end{tabular} & -5.25 & PODIUM & 22.38 & 16 \\
\hline 7 & \begin{tabular}{|l|} 
KP1BX \\
\end{tabular} & \begin{tabular}{|l|}
$350 \times 350 \times 35$ \\
\end{tabular} & -5.25 & PODIUM & 22.38 & 11 \\
\hline 8 & KP1B2X & \begin{tabular}{|l|}
$350 \times 350 \times 35$ \\
\end{tabular} & -5.25 & PODIUM & 23.58 & 1 \\
\hline 9 & KP1B3X & $350 \times 350 \times 35$ & -5.25 & PODIUM & 24.11 & 1 \\
\hline 10 & \begin{tabular}{|l|} 
KP1B4 \\
\end{tabular} & $350 \times 350 \times 35$ & -5.25 & PODIUM & 24.41 & 1 \\
\hline 11 & KP1DX & $350 \times 3502$ & -5.35 & PODIUM & 22.28 & 4 \\
\hline 12 & KP1D2X & 350X350X35 & -5.35 & PODIUM & 24.31 & 4 \\
\hline 13 & KP2A & $500 \times 550 \times 25$ & -5.05 & TOWER & 23.805 & 28 \\
\hline 14 & KP2CX & $550 \times 550 \times 25$ & -5.15 & TOWER & 23.705 & 2 \\
\hline 15 & KP2E & $550 \times 350 \times 25$ & -8.45 & TOWER & 20.405 & 1 \\
\hline 16 & KP1EX & $350 \times 350 \times 35$ & -8.45 & PODIUM & 19.18 & 1 \\
\hline & & & & & TOTAL & 182 \\
\hline
\end{tabular}

Tabel 3.1 Type Kingpost

Sebelum memasukan baja kingpost kedalaman lubang bored pile, peneulis memastikan kingpost harus sesuai dengan type yang akan dipasang, Kingpost harus terlebih dahulu diinfil mengunakan mutu beton Fc'70 mpa (screening), Baja kingpost yang sudah diinfil harus menunggu umur beton $1 \times 24$ jam baru bisa dipasang kedalam lubang bored pile. 

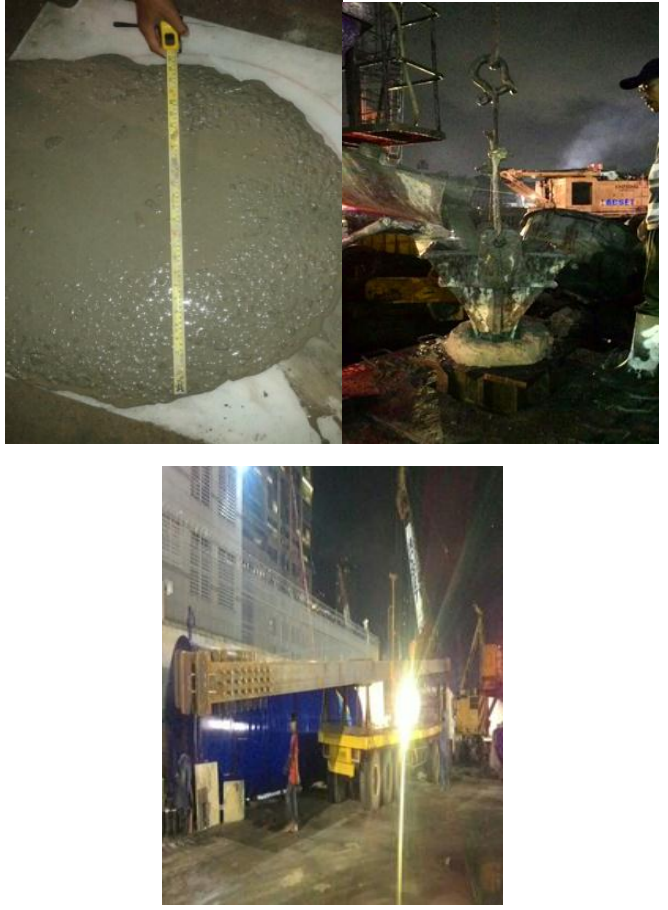

Gambar 3.3 Slump Test Spreading, Infil Kingpost dan Baja Kingpost

\subsection{Follower}

Follower adalah alat bantu untuk mengetahui elevasi top plate pada titik bored pile dengan kingpost dan mengetahui kelurusan kingpost pada saat pemasangan, Panjang flower yang digunakann $6 \mathrm{~s} / \mathrm{d} 10 \mathrm{~m}$.

Follower yang sudah terpasang kedalam lobang bored pile tidak boleh langsung dilepas, Harus menggu 3x24 jam agar baja kingpost bener bener terikat dengan beton didalem lobang bored pile.

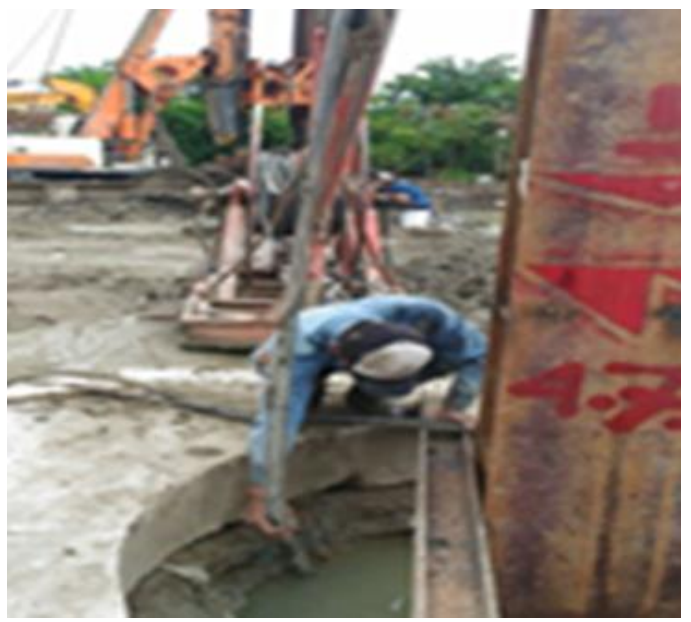

Gambar 3.3 Follower Kingpost

\subsection{Matras Kingpost}

Matras adalah bantalan atau dudukan yang berfungsi untuk meja kingpost, Matras dipasang bersamaan dengan masuk casing saat pengeboran, Guna agar titik koordinat $\mathrm{x}$, y pada casing tidak lari jauh.

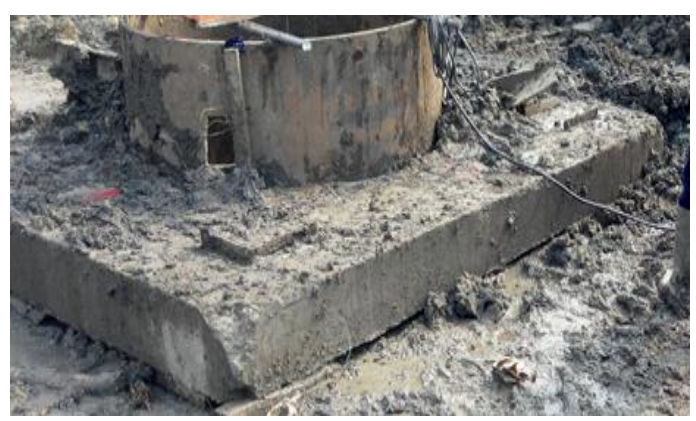

Gambar 3.4 Matras Bantalan Meja Kingpost

\subsection{Meja Kingpost}

Meja kingpost adalah alat untuk memudahkan melihat kelurusan kingpost pada saat pemasangan kingpost, Untuk mengatur kingpost ke arah koordinat sumbuh Y dan X, didalam meja kingpost terdapat sipatan atau tanda yang sudah dibuat oleh tim survey untuk memudahkan pekerjaan pemasang baja kingpost ke lubang bore pile. Setelah selesai pemasangan meja kingpost.

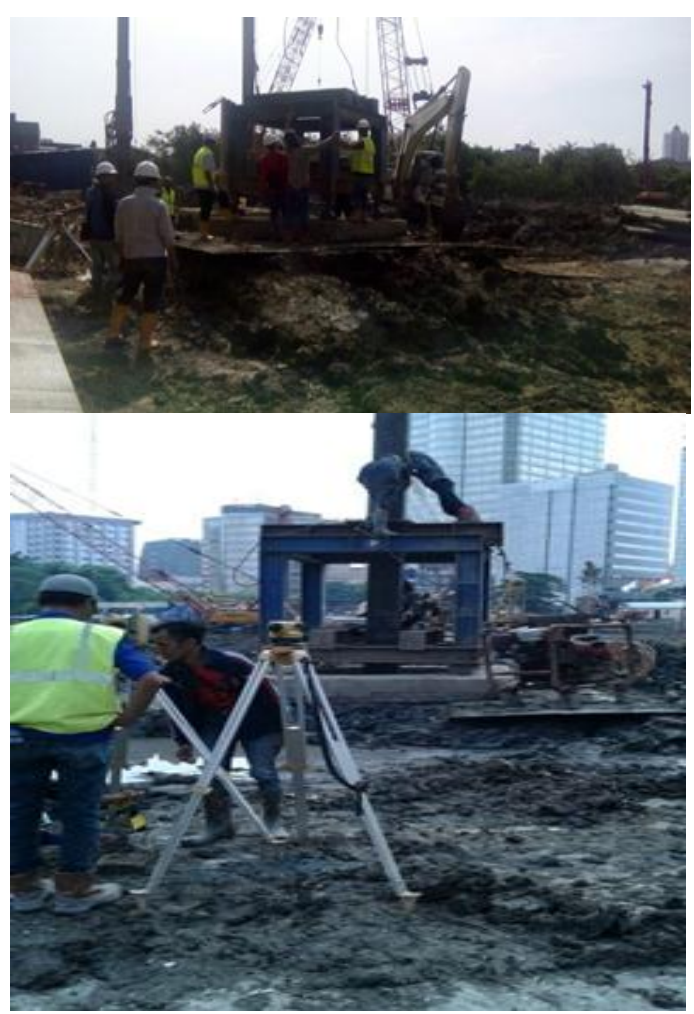

Gambar 3.5 Pemasangan Meja Kingpost \& Mengecek Koordinat X dan Y

\subsection{Baja WF (Beam)}

Setelah pemasangan baja kingpost selesai, Penulis mengecek pegangan flower 
baja kingpost harus dilas mengunakan baja WF (beam) di dua tempat berbeda, dan Pengelasanya harus searah dengan X, dan Y.

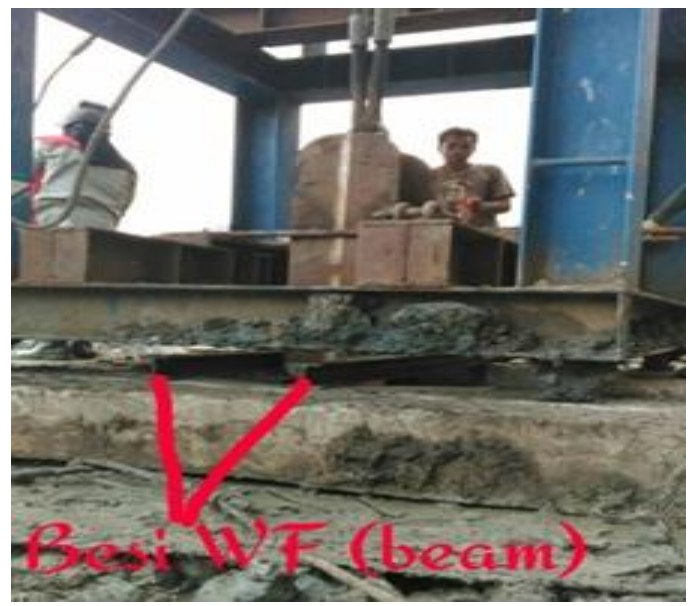

Gambar 3.6 WF (Beam)

\subsection{Sirtu}

Setelah flower diangkat dalam kurang waktu 3x24 jam, penulis mengecek lubang bored pile dengan kingpost harus ditimbun dengan material sirtu (pasir batu) untuk menambah gaya gesek pada baja kingpost, Sehingga tidak terjadi lendutan pada saat pembebanan saat struktur bawah berjalan. Penimbunan dengan material kingpost harus batas maksimal harus diats elevasi top pleat.

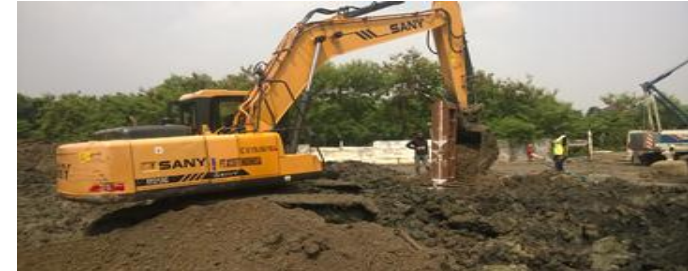

Gambar 3.7 Penimbunan Dengan Material Sirtu

\subsection{Sondir Test}

Titik bore pile dengan kingpost yang sudah di timbun dengan material sirtu (pasir batu) dalam kurang waktu 1x24 jam harus dilakukan pengetesan sondir test untuk melihat kepadatan material yang digunakan. Pada ProyekBangunan Tinggi diambil setiap podasi Bore Pile dengan metode King Post satu titik sondir test titik sama dengan jumlah titik kingpost yang ada pada proyek Bangunan Tinggi

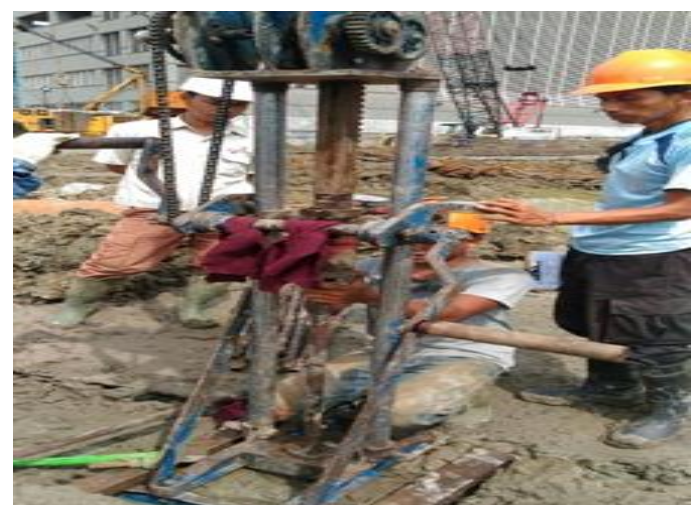

Gambar 3.8 Sondir Test Material Sirtu. 